OPEN ACCESS

Edited by:

Petr Smýkal,

Palacký University Olomouc, Czechia

Reviewed by:

Jan Šafár

Institute of Experimental Botany

(ASCR), Czechia

Federico Valverde,

Consejo Superior de Investigaciones

Cientificas (CSIC), Spain

Jill Christine Preston,

University of Vermont, United States

*Correspondence:

Yin-Gang Hu

huyingang@nwsuaf.edu.cn

tThese authors have contributed equally to this work

Specialty section:

This article was submitted to

Plant Breeding,

a section of the journal

Frontiers in Plant Science

Received: 31 January 2018

Accepted: 20 August 2018

Published: 22 October 2018

Citation:

Chen L, Du Y, Lu Q, Chen H, Meng R, Cui C, Lu S, Yang Y, Chai Y, Li J, Liu L, Qi X, Li H, Mishina K, Yu F

and Hu Y-G (2018) The Photoperiod-Insensitive Allele Ppd-D1a Promotes Earlier Flowering in Rht12 Dwarf Plants of Bread

Wheat. Front. Plant Sci. 9:1312.

doi: 10.3389/fp/s.2018.01312

\section{The Photoperiod-Insensitive Allele Ppd-D1a Promotes Earlier Flowering in Rht12 Dwarf Plants of Bread Wheat}

\author{
Liang Chen ${ }^{1 t}$, Yingying Du't, Qiumei Lu', Hua Chen², Ruishuang Meng ${ }^{1}$, Chunge Cui', \\ Shan Lu', Yang Yang ${ }^{1}$, Yongmao Chai ${ }^{1}$, Juan $\mathrm{Li}^{1}$, Lulu Liu ${ }^{1}$, Xiangning $\mathrm{Qi}^{1}$, Hang Li ${ }^{1}$, \\ Kohei Mishina ${ }^{3}$, Fei Yu ${ }^{4}$ and Yin-Gang Hu ${ }^{1,5 *}$
}

1 State Key Laboratory of Crop Stress Biology in Arid Areas and College of Agronomy, Northwest A\&F University, Xianyang, China, ${ }^{2}$ Department of Agricultural, Food and Nutritional Science, University of Alberta, Edmonton, AB, Canada, ${ }^{3}$ National Institute of Agrobiological Sciences, Tsukuba, Japan, ${ }^{4}$ College of Life Sciences, Northwest A\&F University, Xianyang, China, ${ }^{5}$ Institute of Water Saving Agriculture in Arid Regions of China, Northwest A\&F University, Xianyang, China

The gibberellin-responsive dwarfing gene Rht12 can significantly reduce plant height without changing seedling vigor and substantially increase ear fertility in bread wheat (Triticum aestivum. L). However, Rht12 delays heading date and anthesis date, hindering the use of Rht12 in wheat improvement. To promote early flowering of the Rht12 dwarf plants, the photoperiod-insensitive allele Ppd-D1a was introduced through a cross between Jinmai47 (Ppd-D1a) and Karcagi (Rht12). The results showed that Ppd-D1a can rescue the delaying effect of Rht12 on flowering time and promote earlier flowering by 9.0 days $\left(163.2^{\circ} \mathrm{Cd}\right)$ in the $R h t 12$ dwarf plants by shortening the late reproduction phase. Plant height was reduced by Rht12 (43.2\%) and Ppd-D1a (10.9\%), achieving dwarf plants with higher lodging resistance. Ear fertility, like the grain number per spike, was significantly increased by Rht12 (21.3\%), while it was reduced by Ppd-D1a (6.5\%). However, thousand kernel weight was significantly reduced by Rht12 (12.9\%) but significantly increased by Ppd-D1a (16.9\%). Finally, plant yield was increased by 16.4 and $8.2 \%$, and harvest index was increased by 24.9 and $15.4 \%$ in the Rht12 dwarf lines and tall lines with Ppd-D1a, respectively. Clearly, there was an additive interaction between Rht12 and Ppd-D1 and the introduction of Ppd-D1a advanced the flowering time and improved the yield traits of Rht12 dwarf plants, suggesting that the combination of Rht12 and Ppd-D1a would be conducive to the successful use of Rht12 in wheat breeding programs.

Keywords: Rht12, Ppd-D1a, flowering time, plant height, yield components, wheat

\section{INTRODUCTION}

The introduction of semi-dwarf genes (Rht-B1b and Rht-D1b) into bread wheat (Triticum aestivum. L) was a crucial component of the Green Revolution in the 1970s (Flintham et al., 1997; Hedden, 2003). The higher yields of these semi-dwarf varieties were associated with improved lodging resistance and the resulting ability to tolerate higher rates of chemical fertilizers (Worland et al., 1994). The decrease in stem stature resulted in an increase in assimilate 
partitioning to developing ears, enabling greater floret survival at anthesis and increased grain numbers per ear (Youssefian et al., 1992). Rht-B1b and $R h t-D 1 b$ reduce stem internode length and therefore overall plant height by decreasing the sensitivity of plant tissues to endogenous Gibberellin Acid (GA) (Peng et al., 1999; Sun, 2010). To date, Rht-B1b and Rht-D1b are still the major semi-dwarf genes in wheat breeding, and there are only a few dwarf genes (Rht-B1b, Rht-D1b, and Rht8) successfully applied in wheat breeding projects (Ellis et al., 2004; Botwright et al., 2005; Zhang et al., 2006). Owing to the narrowed genetic background of dwarfing genes, there is a need to broaden dwarf $(R h t)$ genetic resources for wheat production in the future. In the deep sowing conditions, especially in water-limited areas, the semi-dwarf alleles $R h t-B 1 b$ and $R h t-D 1 b$ reduce coleoptile length, seedling vigor, and the capacity to emerge at the seedling stage, leading to low yield and poor final plant biomass (Rebetzke et al., 2001, 2004, 2007; Botwright et al., 2005). In irrigated and fertilized environments, the height reduction effect of $R h t-B 1 b$ and $R h t-D 1 b$ may not be sufficient, and serious lodging could still happen in wheat varieties with these semi-dwarf alleles (Stapper and Fischer, 1990; Berry et al., 2007). Therefore, it is important to include more height reduction genes such as the GA-responsive dwarf gene Rht12 for wheat breeding (Rebetzke et al., 2012a; Chen et al., 2013).

Rht12 is located on the long arm of chromosome $5 \mathrm{~A}$ and can significantly reduce plant height by approximately $40 \%$ without impacting coleoptile length and seedling vigor. Furthermore, Rht12 significantly increased floret fertility, grain number per spike, grain yield, and harvest index (Rebetzke et al., 2012a; Chen et al., 2013). Unfortunately, Rht12 delays ear emergence time (as well as flowering time) by approximately 6 days, and this adverse effect was observed in many environments (Worland et al., 1994; Chen et al., 2013), limiting the use of Rht12 in wheat improvement. It was previously reported that the dominant vernalization gene $V r n-B 1$, which promotes earlier flowering, could not rescue the delaying effects of $R h t 12$ on flowering time, indicating that Rht12 might be epistatic to Vrn-B1 (Chen et al., 2013). Therefore, spike development-related genes should be introduced to promote earlier flowering of the Rht 12 dwarf lines for exploiting the potential of Rht12 in wheat breeding.

The photoperiod genes, which are responsible for photoperiod insensitivity in wheat, play a major role in spike development and flowering time. Genes allelic to $P p d-1$ are located on the homologous group 2 chromosomes (Law et al., 1978). The dominant alleles of photoperiod genes ( $P p d-D 1, P p d-B 1$, and $P p d-A 1)$ showed insensitivity to daylength and accelerated earlier flowering in wheat (Worland et al., 1998). Ppd-D1a, the dominant allele of $P p d-D 1$, which is a member of the pseudo response regulator $(P R R)$ gene family, is the major source of photoperiod insensitivity in wheat cultivars worldwide and can promote earlier ear emergence and flowering compared to its recessive allele Ppd-D1b (Worland et al., 1988; Gonzalez et al., 2005; Wilhelm et al., 2013; Grogan et al., 2016). It was found that allele Ppd-D1a was associated with a 2089-bp deletion in the promoter region that altered the expression of the gene, specifically a loss of its normal circadian regulation. The early flowering phenotype of the Ppd-D1a mutation is likely to be caused by this alteration and the resultant induction of the key floral regulator flowering locus $\mathrm{T}$ (FT) in short or long days (Beales et al., 2007).

The objective of this work was to analyze whether the PpdD1a allele could rescue the delayed effects of Rht12 on plant development and promote earlier flowering in the Rht12 dwarf lines and to explore the interactive effects between $P p d-D 1 a$ and Rht12 on plant height and other agronomic traits.

\section{MATERIALS AND METHODS}

\section{Plant Materials}

A cross was made between two winter bread wheat cultivars Jinmai47 and Karcagi (12). Karcagi (12) is the Rht12 donor (a gamma ray-induced mutant) carrying the photoperiod-sensitive allele $P p d-D 1 b$ as detected by molecular markers (2D-Ins-F1;2DIns-R1/R2) described in Beales et al. (2007). Jinmai47 is a Chinese winter wheat cultivar, widely used in the northwest winter wheat region of China, carrying the photoperiod-insensitive allele PpdDla and the semi-dwarf allele of Rht8 (Wang et al., 2015), which was reported at a distance of $21.7 \mathrm{cM}$ from Ppd-D1 (Gasperini et al., 2012; Chebotar et al., 2013; Wang et al., 2015). Jinmai47 and Karcagi (12) lack any known dominant vernalization genes as detected by molecular markers (VRN1AF, VRN1R; Intr1/A/F2, Intr1/A/R3; Intr1/C/F, Intr1/AB/R; Intr1/B/F, Intr1/B/R3; Intr1/B/F, Intr1/B/R4; Intr1/D/F, Intr1/D/R3; Intr1/D/F, Intr1/D/R4) described in Supplementary Table 1 (Yan et al., 2004; Fu et al., 2005). Additionally, there was no other known dwarfing genes, such as Rht-B1b, Rht-D1b, Rht4, Rht5, or $R h t 13$, etc., in Jinmai47 and Karcagi (12) detected by molecular markers as described in Supplementary Table 1 (Ellis et al., 2002, 2005).

A total of $306 \mathrm{~F}_{2}$ individual lines were derived from the two parents. Based on the corresponding molecular markers of Rht12 (SSR marker: WMS291) (Korzun et al., 1997) and Ppd-D1 (STS marker: 2D-Ins-F1/R1/R2) (Beales et al., 2007), we only selected four homozygous genotypes in the $\mathrm{F}_{2}$ population, which included 18 lines sharing both the dwarf allele Rht12 and the photoperiodinsensitive allele Ppd-D1a (Rht12Rht12Ppd-D1aPpd-D1a, RRPP), 15 lines with the dwarf allele of $R h t 12$ and the photoperiodsensitive allele $P p d-D 1 b$ (Rht12Rht12Ppd-D1bPpd-D1b, RRpp), 16 lines with Ppd-D1a and rht12 (rht12rht12Ppd-D1aPpd-D1a, rrPP), and 13 lines with Ppd-D1b and rht12 (rht12rht12Ppd$D 1 b P p d-D 1 b, \operatorname{rrpp})$. These homozygous plants were used to develop the $\mathrm{F}_{2: 3}, \mathrm{~F}_{3: 4}$, and $\mathrm{F}_{4: 5}$ lines for further analysis.

\section{Field Experiments}

The two parents and the selected 62 lines were planted at the experimental farm of Northwest A\&F University, Xianyang, China $\left(34^{\circ} 17^{\prime} \mathrm{N}, 108^{\circ} 04^{\prime} \mathrm{E}\right.$, at an elevation of $\left.506 \mathrm{~m}\right)$ in the fall of 2014, 2015, and 2016, respectively. Each experiment was conducted under natural photoperiod conditions with the average daylength ranging from 12.6 to $13.5 \mathrm{~h}$ at the late reproductive phase in the experimental farm. To avoid competitive effects between the tall and dwarf plants, the 33 dwarf lines were randomly arranged in a dwarf plot, and the 29 tall lines 
were randomly arranged in a separate tall plot. Each experiment was conducted with two replicates. Experimental plots were $1.0 \mathrm{~m} \times 1.5 \mathrm{~m}$, with four rows spaced $25 \mathrm{~cm}$ apart. Seeds were planted at a distance of $5 \mathrm{~cm}$ between seeds within rows. Supplemental irrigation was provided as needed for avoiding water stress. Insecticides and fungicides were used to prevent insect and disease damage. Weather data were collected by the weather station at this experimental field.

\section{DNA Extraction and Genotyping}

The genomic DNA of the $\mathrm{F}_{2}$ individuals and the two parents were extracted by using the CTAB method (Porebski et al., 1997). The presence of Rht12 was detected with the SSR marker WMS291 (Xgwm291) and the presence of $P p d-D 1$ was checked with STS markers $2 \mathrm{D}$-Ins-F1/R1/R2 in the $\mathrm{F}_{2}$ population, respectively, as described (Korzun et al., 1997; Beales et al., 2007; Chen et al., 2013). Markers were purchased from AuGCT Biotech Co., Ltd, Beijing. Then, the homozygous genotypes at these two loci were selected to develop the $\mathrm{F}_{2: 3}, \mathrm{~F}_{3: 4}$, and $\mathrm{F}_{4: 5}$ lines.

\section{Spike Development and Fertility}

Spike differentiation was investigated every 4 or 7 days using the main shoot of the sampled plants from the five-leaf stage (Z15), for checking the timing of the double ridge formation stage (DR) and the terminal spikelet initiation stage (TS) (Gardner et al., 1985). Three plants were selected from each plot every time and a digital stereo microscope (Nikon, SMZ1500) linked with a digital camera was used for observing and taking pictures. The anthesis dates (Z65) of each line were recorded as that $50 \%$ of the spikes in a plot flowered (Gonzalez et al., 2005; Chen et al., 2013). Thermal time was used for evaluating the progress of spike development. Thermal time was evaluated by the accumulated growing degree day $\left({ }^{\circ} \mathrm{Cd}\right)$, which was recorded as the sum of the daily mean temperature above a base temperature suitable for plant growth from the sowing date through the observed dates to the target phases; here, $0^{\circ} \mathrm{C}$ was selected as the base temperature (Shaykewich, 1995; Gonzalez et al., 2005; Ibrahim et al., 2009).

At anthesis, the main shoot spike of five plants from each plot were randomly selected to count the number of fertile florets. Stigmatic branches of florets spread wide with either green anthers or with pollen grains present on them were considered fertile (Waddington et al., 1983).

\section{Plant Height and Internode Characteristics}

Five plants per plot were randomly selected for measuring the leaf number of the main shoot (Haun, 1973). Peduncle length $(\mathrm{cm})$ and plant height $(\mathrm{cm})$ were measured at maturity. Lodging was scored at maturity from the fraction of the area affected and the severity of lodging in those areas. This degree of lodging is judged as the angle from the vertical. That is, going from 0 for a standing crop to 90 for a crop flat on the ground. The lodging score is then the proportion of the area affected multiplied with the degree of lodging (Zadoks et al., 1974).

\section{Yield and Yield Components}

Ten plants were randomly selected per plot for collecting the data of grain number per spike, spikelet number per spike, and fertile shoot number per plant at maturity. Before the harvest, approximately 20 to 45 plants remained in each line because of the frequent sampling, and these plants were used for measuring the biomass per plant, grain yield per plant, harvest index, and thousand kernel weight (for details see Chen et al., 2013).

\section{Data Analysis}

The mean values of all the investigated traits for the four genotypes (RRPP, RRpp, rrPP, and rrpp) were calculated and statistical analysis was carried out by analysis of variance (ANOVA) using the statistical package SPSS 18.0, as outlined in previous studies (Liu et al., 2017; Chen et al., 2018). ANOVA was initially performed on the yearly data and combined environments over the 3 years. Each genotype was considered as a fixed effect to calculate mean, while the replication was treated as a random effect in each year. For the combined model, year was also considered as a random effect. Pairwise multiple comparisons were detected using a protected least significant differences (LSD) test at $\alpha=0.05$. The relative effects of dwarf genes were estimated by using the formula: effect $=\left(\right.$ Mean $_{\mathrm{dwarf}}-$ Mean $\left._{\text {tall }}\right) /$ Mean $_{\text {tall }} \times 100 \%$.

\section{RESULTS}

\section{Molecular Marker Detection of Rht12 and Ppd-Da}

The homozygous genotypes of Rht12 and Ppd-D1 in the $\mathrm{F}_{2}$ segregating population were classified based on the presence or absence of their linked SSR and STS markers (Figure 1). Homozygous individuals at these two loci were selected and used to develop the $\mathrm{F}_{2: 3}, \mathrm{~F}_{3: 4}$, and $\mathrm{F}_{4: 5}$ lines for further analysis.

\section{ANOVA of All Traits Among Parents and the Four Genotypes}

On average, the taller parent Jinmai47 ( $\mathrm{rPP}$ ) was $20.7 \mathrm{~cm}$ higher than the dwarf donor parent Karcagi (RRpp) over the 3 years. Jinmai47 also showed less grain number per spike but better yield and yield-associated traits than Karcagi. Transgressive segregation was found in the population for all traits and all the traits were significant $(P<0.01)$ from 2014 to 2016 except florets initiated per spikelet $(P=0.4)$ and florets initiated per spike $(P=0.03)$ (Table 1). Parent Jimmai47 shared the same genotype with 16 lines for the $P p d-D 1$ and Rht12 genes. Jinmai47 was $18.3 \mathrm{~cm}$ shorter than the progenies and had a shorter peduncle length with a better lodging score. In addition, 15 lines had the same genotype with Karcagi, and the progenies were similar on the traits we recorded but better on fertility (Table 1).

\section{Plant Height and Associated Traits}

The plant height of the dwarf lines (RR) was significantly shorter than the tall lines (rr) by an average of $44.1 \mathrm{~cm}(41.3 \%), 51.8 \mathrm{~cm}$ (44.6\%), and $52.6 \mathrm{~cm}(43.7 \%)$ in $\mathrm{F}_{2: 3}, \mathrm{~F}_{3: 4}$, and $\mathrm{F}_{4: 5}$ (Table 2), 

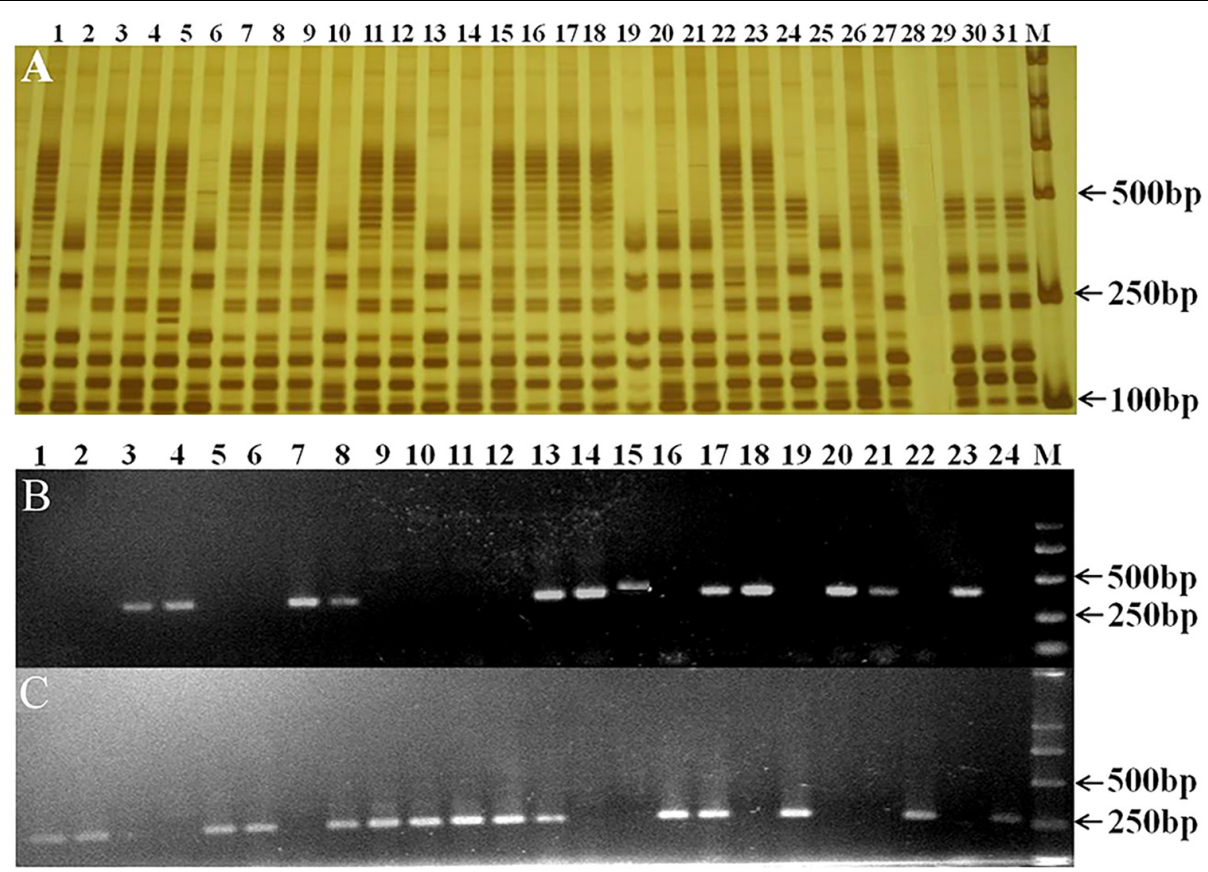

FIGURE 1 | Detection of the dwarf gene Rht12 and photoperiod gene Ppd-D1 with SSR marker WMS291 (A) and STS markers 2D-Ins-F1/R1/R2 (B,C) in some plants from the $F_{2}$ population. (A) 24, 29, 30, 31, homozygous dwarfing individuals (Rht12Rht12); 2, 6, 10, 13, 14, 19, 20, 21, 25, homozygous tall individuals (rht12rht12); 28, no amplification observed; the others were heterozygous individuals (Rht12rht12). (B,C) 1, 2, 5, 6, 9, 10, 11, 12, 16, 19, 22, 24, homozygous individuals with Ppd-D1a; 3, 4, 7, 14, 15, 18, 20, 21, 23, homozygous individuals with Ppd-D1b; the others were heterozygous individuals (Ppd-D1a Ppd-D1b). M: marker DL2000.

TABLE 1 | Mean and analysis of variance of all traits among parents and the four genotypes on Rht12 and Ppd-D1 during $2014-2016$.

\begin{tabular}{|c|c|c|c|c|c|c|c|c|c|}
\hline \multirow[t]{2}{*}{ Traits } & \multicolumn{3}{|c|}{ Parents } & \multicolumn{6}{|c|}{ Population $(n=62)$} \\
\hline & Jinmai47 & Karcagi & Diff. & RRPP & RRpp & rrPP & rrpp & $F$-value & $P$-value \\
\hline Plant height (cm) & 89.5 & 68.8 & 20.7 & 60.8 & 69.0 & 107.8 & 119.3 & 213.6 & $<0.0001$ \\
\hline peduncle length (cm) & 26.7 & 23.8 & 2.8 & 21.6 & 24.1 & 35.2 & 42.1 & 7.1 & 0.0001 \\
\hline Lodging score & 1.7 & 10.0 & -8.3 & 0.0 & 1.7 & 23.3 & 50.0 & 5.3 & $<0.0001$ \\
\hline Thermal time $\left({ }^{\circ} \mathrm{Cd}\right)$ from sowing to anthesis & 1448.3 & 1834.0 & -385.7 & 1530.2 & 1693.4 & 1483.8 & 1663.9 & 556.5 & $<0.0001$ \\
\hline Spikelets spike ${ }^{-1}$ & 20.7 & 19.7 & 1.0 & 19.0 & 19.5 & 20.4 & 21.1 & 43.2 & $<0.0001$ \\
\hline Florets initiated spikelet ${ }^{-1}$ & 9.0 & 9.5 & -0.5 & 9.3 & 9.5 & 9.5 & 9.7 & 0.9 & 0.4128 \\
\hline Florets initiated spike ${ }^{-1}$ & 199.2 & 190.2 & 9.0 & 176.1 & 180.0 & 192.2 & 197.7 & 2.3 & 0.0301 \\
\hline Fertile florets spike ${ }^{-1}$ & 52.0 & 55.0 & -3.0 & 49.7 & 54.9 & 45.3 & 48.8 & 113.0 & $<0.0001$ \\
\hline Fertility* (\%) & 25.2 & 28.3 & -3.1 & 28.2 & 30.6 & 23.7 & 25.5 & 62.9 & $<0.0001$ \\
\hline Spike length (cm) & 10.4 & 12.9 & -2.6 & 9.9 & 10.4 & 10.7 & 12.4 & 8.0 & $<0.0001$ \\
\hline Efficient spikes plant ${ }^{-1}$ & 6.0 & 9.4 & -3.4 & 7.6 & 7.5 & 6.5 & 5.9 & 8.3 & $<0.0001$ \\
\hline Grain No. spike ${ }^{-1}$ & 47.6 & 50.1 & -2.5 & 42.7 & 44.5 & 39.3 & 41.0 & 12.4 & $<0.0001$ \\
\hline TKW (g) & 48.0 & 35.0 & 13.0 & 41.9 & 35.4 & 45.7 & 42.3 & 37.6 & $<0.0001$ \\
\hline Yield (g) & 15.6 & 11.6 & 4.0 & 14.4 & 12.6 & 15.4 & 14.4 & 16.2 & $<0.0001$ \\
\hline Biomass (g) & 40.4 & 34.4 & 6.0 & 35.0 & 38.0 & 41.3 & 44.0 & 18.5 & $<0.0001$ \\
\hline Harvest index (\%) & 40.5 & 33.3 & 7.2 & 40.3 & 32.5 & 37.8 & 32.8 & 28.4 & $<0.0001$ \\
\hline
\end{tabular}

* Fertility is estimated as the ratio of fertility florets to total florets per spike of the main shoot spike.

respectively. However, in the dwarf lines (RR), the plant height of RRPP was reduced by $7.6 \mathrm{~cm}(11.1 \%)$ on average compared with that of the RRpp lines across the three generations. In the tall lines (rr), the plant height of the $\operatorname{rrPP}$ was reduced by $12.9 \mathrm{~cm}$ $(10.7 \%)$ on average compared with that of the rrpp lines across the three generations (Table 2 and Figure 2). It is clear that the dominant $P p d-D 1 a$ allele decreases plant height in both the dwarf and tall lines, though its effect is much weaker than that of Rht 12 .

The culm of tall lines elongated faster than that of Rht12 dwarf lines from the seedling stage, and the final plant stature 
TABLE 2 | Plant height and lodging score of the four groups of wheat lines in the 3-year experiments.

\begin{tabular}{|c|c|c|c|c|c|c|c|}
\hline Progeny & Traits & RRPP & RRpp & rrPP & rrpp & Jinmai47 & Karcagi \\
\hline \multirow[t]{3}{*}{$F_{2: 3} 2014-2015$} & Plant height $(\mathrm{cm})$ & $58.3 \pm 5.6 d$ & $67.2 \pm 4.7 c$ & $98.1 \pm 6.5 b$ & $115.7 \pm 7.0 \mathrm{a}$ & $89.7 \pm 2.2$ & $68.6 \pm 3.2$ \\
\hline & Peduncle length (cm) & $19.5 \pm 2.4 d$ & $22.7 \pm 3.0 c$ & $32.6 \pm 3.3 b$ & $40.0 \pm 4.1 \mathrm{a}$ & $25.5 \pm 1.3$ & $23.4 \pm 2.8$ \\
\hline & Lodging score (\%) & 0.0 & 0.0 & 20.0 & 45.0 & 0.0 & 0.0 \\
\hline \multirow[t]{3}{*}{$F_{3: 4} 2015-2016$} & Plant height (cm) & $60.8 \pm 3.9 d$ & $67.6 \pm 5.0 c$ & $110.2 \pm 5.0 b$ & $121.7 \pm 5.8 a$ & $91.4 \pm 3.1$ & $71.5 \pm 2.8$ \\
\hline & Peduncle length (cm) & $22.8 \pm 2.0 d$ & $25.5 \pm 2.5 c$ & $35.7 \pm 2.7 b$ & $42.5 \pm 3.6 a$ & $26.2 \pm 1.4$ & $24.8 \pm 2.0$ \\
\hline & Lodging score (\%) & 0.0 & 5.0 & 45.0 & 90.0 & 10.0 & 0.0 \\
\hline \multirow[t]{3}{*}{$F_{4: 5} 2016-2017$} & Plant height (cm) & $64.2 \pm 4.5 d$ & $71.3 \pm 4.3 c$ & $115.6 \pm 5.1 b$ & $125.1 \pm 5.5 a$ & $91.7 \pm 2.0$ & $73.0 \pm 3.8$ \\
\hline & Peduncle length (cm) & $20.7 \pm 1.6 d$ & $23.2 \pm 3.3 c$ & $36.6 \pm 4.0 b$ & $45.5 \pm 3.4 a$ & $27.8 \pm 1.2$ & $24.1 \pm 3.0$ \\
\hline & Lodging score (\%) & 0.0 & 0.0 & 5.0 & 30.0 & 5.0 & 0.0 \\
\hline
\end{tabular}

All data are represented as mean $\pm S D$ of each genotype. Different letters ("a," "b," "c," and " $d$ ") within rows indicate differences significant between different genotypes at $P<0.05$; parents were not included.

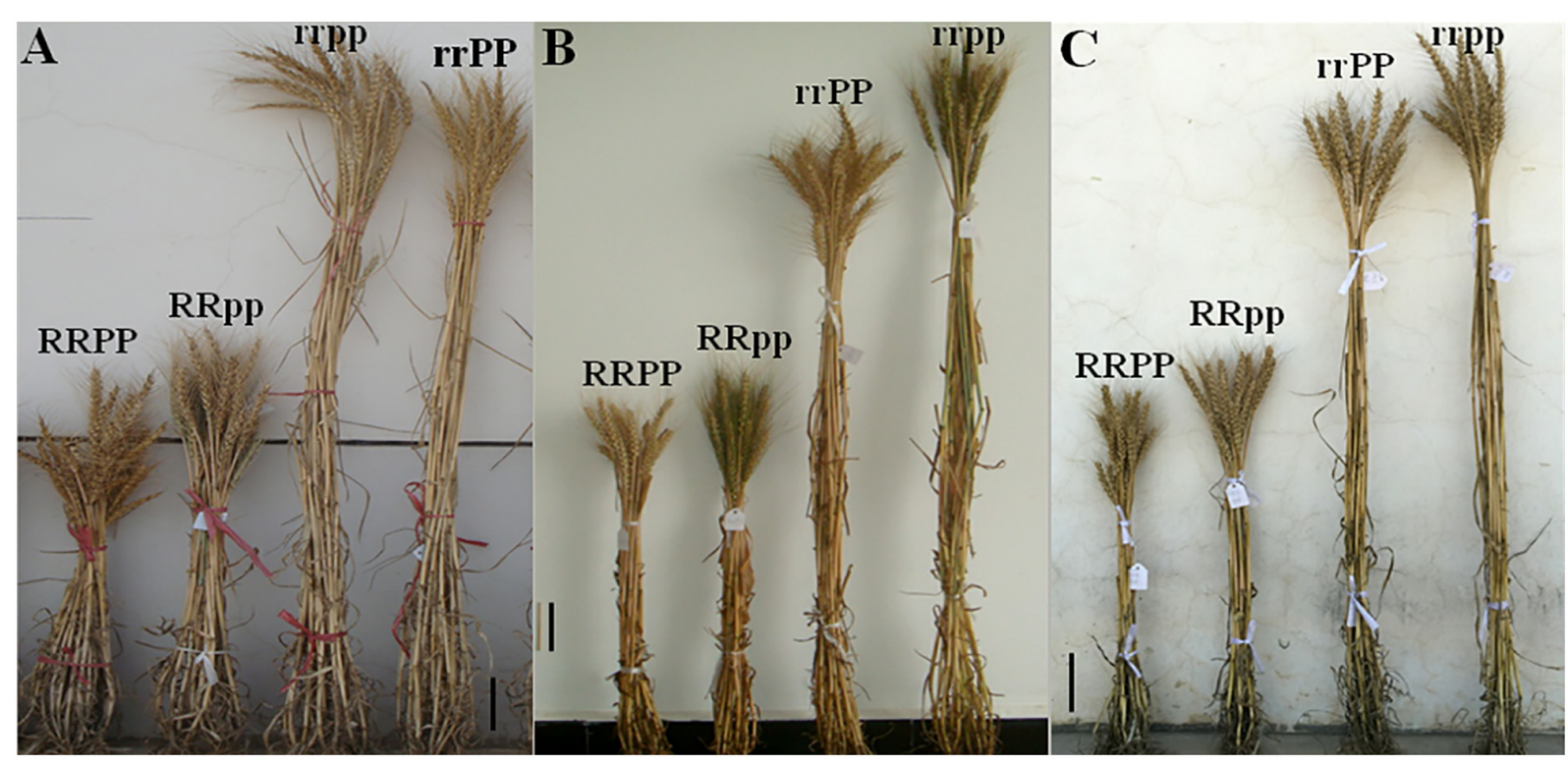

FIGURE 2 | Plant morphology of the four groups of the $F_{2: 3}, F_{3: 4}$, and $F_{4: 5}$ lines at maturity. (A-C) Plant morphology of the four groups of the $F_{2: 3}$, $F_{3: 4}$, and $F_{4: 5}$ lines in the 2014-2015, 2015-2016, and 2016-2017 growing seasons, respectively. Scale bar $=10 \mathrm{~cm}$.

of Rht12 dwarf lines was shortened through the reduction of the length of the internodes, especially the reduction of the peduncle length. The peduncle length of the RR lines was reduced by $16.3 \mathrm{~cm}(42.0 \%)$ on average compared to that of the tall lines (rr) across the three generations (Table 2). Additionally, the PpdD1a allele showed a reducing effect on peduncle length that was much weaker than that of Rht12. The peduncle length of the RRPP group was shorter than that of the RRpp group by $2.8 \mathrm{~cm}(11.8 \%)$; the peduncle length of the rrPP group was shorter than that of the rrpp group by $7.7 \mathrm{~cm}(18.0 \%)$ across the three successive generations, respectively (Table 1). The plant height was reduced by either Rht12 or Ppd-D1a through a reduction of the length of each internode instead of a reduction of the number of internodes (both the tall and dwarf plants have 5 internodes, data not shown). Finally, the dwarf plants had greater resistance to lodging, probably due to the dwarf stature and the shorter internodes, whereas serious lodging only occurred in the tall lines.

\section{Spike Development and Flowering Time}

For all the three generations of progeny, the duration of the sowing - double ridge formation stage (SW-DR) of the Rht12 dwarf lines was longer than that of the tall lines, while there was no significant difference between the RRPP and RRpp, and the rrPP and rrpp groups (Table 3 ). Compared to the tall lines (rr) in $\mathrm{F}_{2: 3}, \mathrm{~F}_{3: 4}$, and $\mathrm{F}_{4: 5}$, the dwarf (RR) lines require an additional $45.7^{\circ} \mathrm{Cd}$ (7.0 days), $32.2^{\circ} \mathrm{Cd}$ (7.0 days), and $47.6^{\circ} \mathrm{Cd}$ (6.5 days), respectively, to reach the double ridge stage. These results indicated that $P p d-D 1 a$ did not significantly affect the duration of the vegetative phase (SW-DR period), though the lines with $P p d-D 1 a$ had a shorter duration of the SW-DR period than the lines with $P p d-D 1 b$. Finally, due to the longer duration of the vegetative phase (SW-DR period), the dwarf plants produced more leaves than the tall plants in all the three generations of progeny (Table 3 ). 
TABLE 3 | Thermal time $\left({ }^{\circ} \mathrm{Cd}\right)$ and duration days $(\mathrm{d})$ of different developmental phases of the four genotypes of the $\mathrm{F}_{2: 3}$, $\mathrm{F}_{3: 4}$, and $\mathrm{F}_{4: 5}$ lines.

\begin{tabular}{|c|c|c|c|c|c|c|}
\hline Progeny & Genotype/ variety & SW-DR & DR-TS & TS-AN & SW-AN & Total leaf number \\
\hline \multirow[t]{6}{*}{$F_{2: 3} 2014-2015$} & RRPP & 779.6(155.0)a & 187.2(16.0)b & $594.8(41.0) \mathrm{c}$ & 1561.6(212.0)c & $13.1 \mathrm{a}$ \\
\hline & RRpp & 790.6(156.0)a & 204.2(17.0)a & 779.9(48.0)a & 1714.9(221.0)a & $13.6 \mathrm{a}$ \\
\hline & rrPP & $731.8(147.0) b$ & $156.0(18.0) \mathrm{c}$ & 609.4(43.0)c & 1497.2(208.0)d & $12.0 \mathrm{~b}$ \\
\hline & rrpp & $746.9(150.0) b$ & 189.7(19.0)b & $745.8(50.0) b$ & 1682.4(219.0)b & $12.0 \mathrm{~b}$ \\
\hline & Karcagi & 857.3(162.0) & 230.4(18.0) & 795.3(49.0) & 1883.0(229.0) & 15.3 \\
\hline & Jinmai47 & $724.1(145.0)$ & 133.2(17.0) & $610.7(44.0)$ & 1468.0(206.0) & 11.7 \\
\hline \multirow[t]{6}{*}{$F_{3: 4} 2015-2016$} & RRPP & 788.3(148.0)a & 162.2(19.0)c & $566.0(41.0) \mathrm{c}$ & 1516.5(208.0)c & $12.5 \mathrm{a}$ \\
\hline & RRpp & 797.1(150.0)a & 207.7(23.0)a & $672.1(44.0) \mathrm{a}$ & 1676.9(217.0)a & $12.2 \mathrm{a}$ \\
\hline & rrPP & $750.5(140.0) c$ & $143.2(22.0) d$ & $587.1(44.0) \mathrm{c}$ & 1480.8(206.0)d & $11.2 \mathrm{~b}$ \\
\hline & rrpp & 770.5(144.0)b & 180.0(23.0)b & 711.4(49.0)b & 1661.9(216.0)b & $11.5 b$ \\
\hline & Karcagi & 837.4(157.0) & 248.2(22.0) & 726.3(45.0) & 1811.9(224.0) & 16.0 \\
\hline & Jinmai47 & $746.7(139.0)$ & $131.7(21.0)$ & $559.4(44.0)$ & 1437.8(204.0) & 10.2 \\
\hline \multirow[t]{6}{*}{$F_{4: 5} 2016-2017$} & RRPP & 796.9(150.0)a & 163.0(18.0)b & $552.7(38.0) \mathrm{c}$ & 1512.6(206.0)c & $13.3 \mathrm{a}$ \\
\hline & RRpp & 836.3(154.0)a & 203.9(22.0)a & 648.2(39.0)a & 1688.4(215.0)a & $13.5 \mathrm{a}$ \\
\hline & rrPP & $755.9(145.0) b$ & 153.6(19.0)c & $554.1(39.0) \mathrm{c}$ & 1473.5(204.0)d & $12.3 b$ \\
\hline & rrpp & $782.2(148.0) b$ & 200.5(22.0)a & $664.8(43.0) b$ & 1647.5(213.0)b & $12.2 \mathrm{~b}$ \\
\hline & Karcagi & 864.6(159.0) & 238.3(21.0) & $706.2(42.0)$ & 1809.1(222.0) & 15.1 \\
\hline & Jinmai47 & $748.2(144.0)$ & 150.3(19.0) & $540.6(39.0)$ & 1439.1(202.0) & 11.0 \\
\hline
\end{tabular}

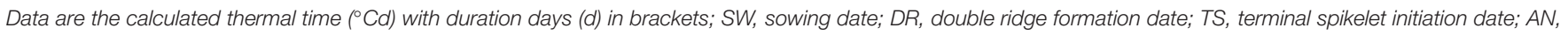

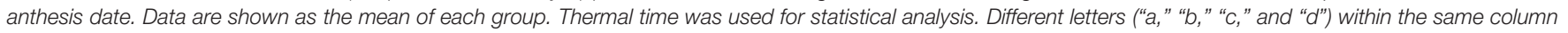
represent differences significant at $P<0.05$; parents were not included.

However, after the vegetative phase, $P p d-D 1 a$ showed a significant effect on the subsequent developmental phases, double ridge stage (DR) to TS and to anthesis stage (AN). Actually, quantitative trait loci (QTL) analysis was conducted using this $\mathrm{F}_{2}$ population (306 plants). Results revealed that the locus of $P p d-D 1$ explained approximately $70.0 \%$ of the flowering time variation, indicating that $P p d-D 1$ is a major locus for flowering time in this population. RRPP lines required less thermal time to complete the DR-TS period and reached the TS stage $34.5^{\circ} \mathrm{Cd}$ on average earlier than the RRpp lines across $\mathrm{F}_{2: 3}, \mathrm{~F}_{3: 4}$, and $\mathrm{F}_{4: 5}$ (Table 3). Additionally, $P p d-D 1 a$ accelerated the developmental progress of the reproductive phase in the tall lines. The duration of the DR-TS period of the $\operatorname{rrPP}$ group was $39.1^{\circ} \mathrm{Cd}$ on average shorter than that of the rrpp group across the three generations. Moreover, for the duration of TS-AN period, RRPP had shorter TS-AN period by $128.9^{\circ} \mathrm{Cd}$ than the RRpp group, whereas the rrPP group showed a shorter duration of TS-AN than the rrpp group by $123.8^{\circ} \mathrm{Cd}$ across the three generations. These results indicated that either the dwarf or tall plants carrying $P p d-D 1 a$ had a shorter duration of DR-AN period. Finally, the RRPP and rrPP lines flowered earlier by $163.2^{\circ} \mathrm{Cd}$ (9.0 days) and $180.1^{\circ} \mathrm{Cd}$ (10.0 days) on average than the RRpp and rrpp lines, respectively, across the three generations (Table 3 and Figure 3). It was therefore clear that the reproductive phase can be strongly affected by $P p d-D 1 a$ in both the dwarf and tall plants, without significantly affecting the vegetative phase.

\section{Floret Fertility}

In the three generations, the number of spikelets per spike of the dwarf lines (RRPP and RRpp) was significantly lower by $1.5(7.3 \%)$ on average than the tall lines (rrPP and rrpp), while no significant difference was observed between the PP and pp genotypes (Table 4). However, there was no significant difference observed between the four genotypes in the number of florets initiated per spikelet. Generally, 9 to 10 florets could be initiated per spikelet. Finally, the tall plants achieved larger numbers of florets per spike than the dwarf plants owing to their larger number of spikelets per spike. Additionally, the pp plants had more florets per spike than the PP plants in all the three generations (Table 4). $P P d-D 1 b$ likely played a major role in determining more floret numbers in both the tall and dwarf lines.

The dwarf plants produced 5.5 (11.0\%), 6.1 (13.9\%), and $3.5(7.1 \%)$ more fertile florets per spike than the tall plants in $\mathrm{F}_{2: 3}, \mathrm{~F}_{3: 4}$, and $\mathrm{F}_{4: 5}$, respectively. Additionally, the pp genotype achieved more fertile florets per spike than the PP genotype by $10.7 \%$ in the dwarf lines and $7.9 \%$ in the tall lines, among the three generations (Table 4). Finally, the ear fertility of the RR groups was significantly increased by $22.9,23.4$, and $17.6 \%$ than that of the rr groups in the three generations, respectively. Additionally, RRpp achieved higher fertility than RRPP, and rrpp also had higher fertility than rrPP in the three generations. This suggested that both Rht12 (RR) and PPd-D1b (pp) could increase ear fertility, and the combination of RR and pp had a stronger potential in improving floret fertility than the other three genotypes.

\section{Yield and Yield Components}

The spike length of RR was shorter than that of rr by an average of $8.2 \%$, across the three generations. Moreover, in the dwarf lines, the spike length of RRpp was longer by an average of $1.4 \mathrm{~cm}$ (13.8\%) than that of RRPP; in the tall lines, the spike length of 


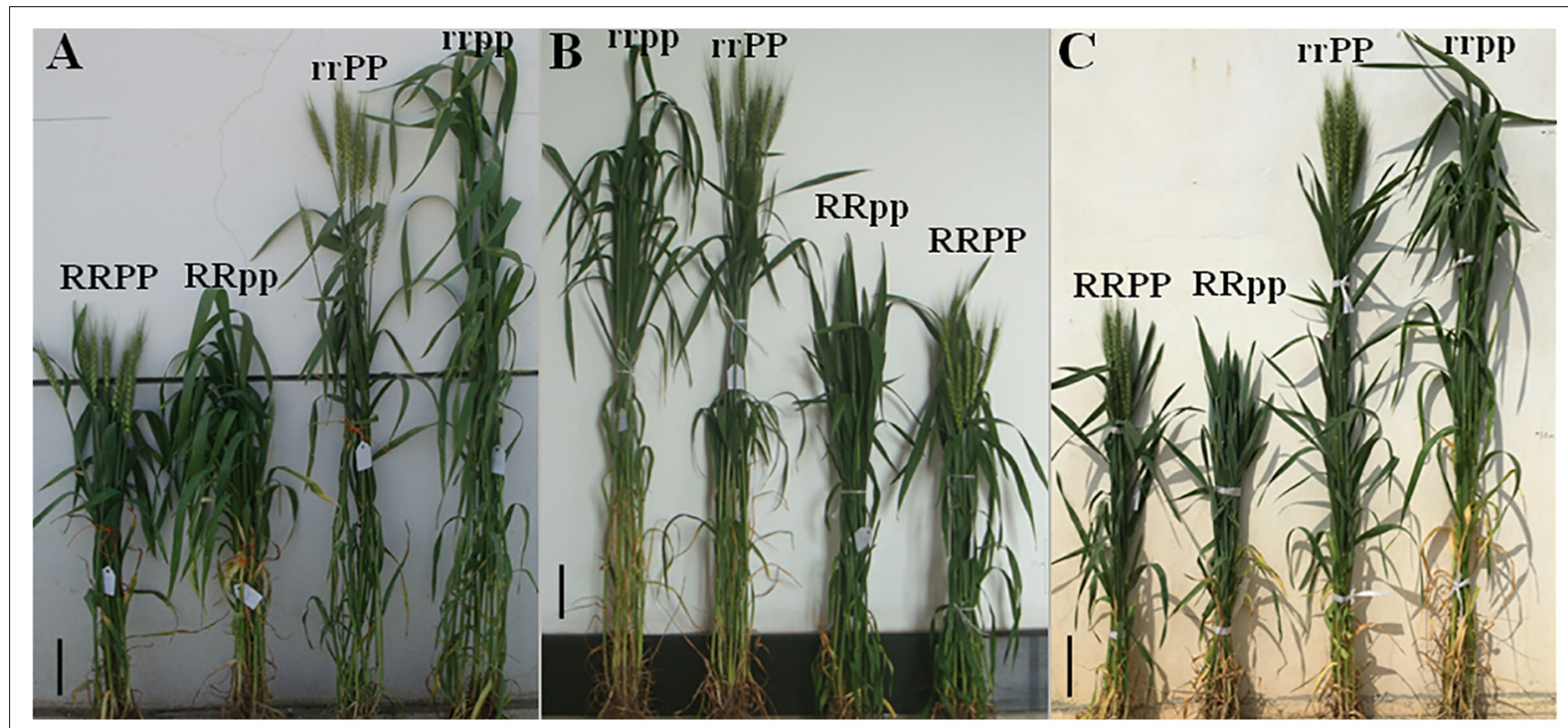

FIGURE 3 | Plant morphology of the four groups (RRPP, RRpp, rrPP, and rrpp) of the $\mathrm{F}_{2: 3}, \mathrm{~F}_{3: 4}$, and $\mathrm{F}_{4: 5}$ lines at the heading (or anthesis) stage. (A-C) Plant morphology of the four groups of wheat $F_{2: 3}, F_{3: 4}$, and $F_{4: 5}$ lines in the 2014-2015, 2015-2016, and 2016-2017 growing seasons, respectively. The RRPP and rrPP plants have headed and some plants have even flowered, while the RRpp and rrpp plants have just reached the heading stage, and some plants are still at the late booting stage. Scale bar $=10 \mathrm{~cm}$.

TABLE 4 | Spike characters of the four genotypes of the $F_{2: 3}, F_{3: 4}$, and $F_{4: 5}$ lines.

\begin{tabular}{|c|c|c|c|c|c|c|c|}
\hline \multirow[t]{2}{*}{ Progeny } & & \multicolumn{6}{|c|}{ Genotype/variety } \\
\hline & & RRPP & RRpp & rrPP & rrpp & Jinmai47 & Karcagi \\
\hline \multirow[t]{5}{*}{$F_{2: 3}(2014-2015)$} & Spikelets spike ${ }^{-1}$ & $19.2 \pm 1.3 \mathrm{a}$ & $19.6 \pm 1.5 \mathrm{a}$ & $20.7 \pm 1.0 b$ & $21.0 \pm 1.7 b$ & $22.3 \pm 1.6$ & $19.0 \pm 1.0$ \\
\hline & Florets initiated spikelet ${ }^{-1}$ & $9.5 \pm 1.3 a$ & $10.0 \pm 1.1 \mathrm{a}$ & $9.4 \pm 0.8 a$ & $9.8 \pm 1.0 \mathrm{a}$ & $9.3 \pm 1.0$ & $9.4 \pm 1.2$ \\
\hline & Florets initiated spike ${ }^{-1}$ & $186.4 \pm 5.0 c$ & $193.0 \pm 4.6 b$ & $200.1 \pm 7.1 \mathrm{a}$ & $206.2 \pm 6.2 \mathrm{a}$ & $210.1 \pm 5.4$ & $183.7 \pm 6.0$ \\
\hline & Fertile florets spike ${ }^{-1}$ & $52.0 \pm 1.8 \mathrm{~b}$ & $58.1 \pm 2.0 a$ & $47.0 \pm 1.6 c$ & $52.1 \pm 2.2 b$ & $53.6 \pm 2.4$ & $57.0 \pm 2.8$ \\
\hline & Fertility* & $0.28 \pm 0.01 b$ & $0.31 \pm 0.01 a$ & $0.23 \pm 0.01 d$ & $0.25 \pm 0.01 c$ & $0.26 \pm 0.01$ & $0.31 \pm 0.02$ \\
\hline \multirow[t]{5}{*}{$F_{3: 4}(2015-2016)$} & Spikelets spike ${ }^{-1}$ & $19.0 \pm 1.0 \mathrm{a}$ & $19.3 \pm 1.2 \mathrm{a}$ & $20.2 \pm 1.5 b$ & $20.6 \pm 1.0 b$ & $21.0 \pm 1.2$ & $20.0 \pm 1.3$ \\
\hline & Florets initiated spikelet ${ }^{-1}$ & $9.1 \pm 0.5 a$ & $9.0 \pm 1.0 \mathrm{a}$ & $9.5 \pm 0.8 a$ & $9.2 \pm 1.1 \mathrm{a}$ & $9.6 \pm 0.6$ & $8.9 \pm 0.5$ \\
\hline & Florets initiated spike ${ }^{-1}$ & $171.0 \pm 3.2 \mathrm{c}$ & $176.1 \pm 5.0 \mathrm{c}$ & $183.6 \pm 4.5 b$ & $190.7 \pm 3.3 a$ & $200.1 \pm 6.0$ & $181.4 \pm 5.1$ \\
\hline & Fertile florets spike ${ }^{-1}$ & $47.2 \pm 2.0 \mathrm{~b}$ & $52.1 \pm 2.3 a$ & $42.2 \pm 2.4 d$ & $45.0 \pm 3.0 c$ & $50.0 \pm 3.4$ & $53.1 \pm 4.1$ \\
\hline & Fertility* & $0.28 \pm 0.01 b$ & $0.30 \pm 0.02 a$ & $0.23 \pm 0.01 d$ & $0.24 \pm 0.01 c$ & $0.25 \pm 0.01$ & $0.29 \pm 0.01$ \\
\hline \multirow[t]{5}{*}{$F_{4: 5}(2016-2017)$} & Spikelets spike ${ }^{-1}$ & $19.0 \pm 1.5 \mathrm{a}$ & $19.5 \pm 1.0 \mathrm{a}$ & $20.8 \pm 1.6 b$ & $21.3 \pm 1.2 b$ & $21.2 \pm 1.4$ & $19.4 \pm 1.1$ \\
\hline & Florets initiated spikelet ${ }^{-1}$ & $9.0 \pm 0.5 b$ & $9.7 \pm 1.0 \mathrm{a}$ & $9.6 \pm 1.0 \mathrm{a}$ & $9.9 \pm 0.7 a$ & $9.0 \pm 1.0$ & $9.5 \pm 0.6$ \\
\hline & Florets initiated spike ${ }^{-1}$ & $170.3 \pm 4.2 d$ & $177.6 \pm 5.3 c$ & $192.5 \pm 4.6 b$ & $197.1 \pm 5.5 a$ & $190.5 \pm 5.0$ & $195.4 \pm 4.3$ \\
\hline & Fertile florets spike ${ }^{-1}$ & $50.0 \pm 3.2 b$ & $55.1 \pm 4.0 a$ & $47.6 \pm 3.7 c$ & $50.5 \pm 2.6 b$ & $49.5 \pm 2.9$ & $55.0 \pm 3.6$ \\
\hline & Fertility* & $0.29 \pm 0.01 b$ & $0.31 \pm 0.01 a$ & $0.25 \pm 0.01 d$ & $0.26 \pm 0.01 c$ & $0.26 \pm 0.01$ & $0.28 \pm 0.01$ \\
\hline
\end{tabular}

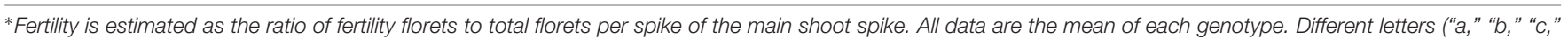
and " $d$ ") within rows indicate differences significant at $P<0.05$; parents were not included.

rrpp was longer by an average of $1.7 \mathrm{~cm}(15.6 \%)$ than that of $\mathrm{rrPP}$ in the three generations (Table 5). It was indicated that the $P p d$ $D 1 a$ allele and Rht12 would decrease spike length. The number of spikelets per spike of the pp plants was larger than that of the PP plants in both the dwarf and tall groups, while Rht12 only had a weak effect. However, the RR genotype produced more efficient spikes $(1.37 ; 22.2 \%)$ than the rr genotype, while no significant difference was observed between the PP and pp genotypes in the three generations, suggesting that $R h t 12$ has a positive effect on this trait. Grain number per spike of the Rht12 dwarf lines (RR) was significantly higher than that of the tall lines (rr) by an average of $3.5(8.6 \%)$. Additionally, pp plants also showed a stronger effect on grain number per spike; pp plants had more grains per spike than PP plants in both the dwarf (5.2\%) and tall groups (5.0\%) (Table 5), indicating that Rht12 and Ppd-D1b both contributed to producing more grains per spike. 
TABLE 5 | Yield-related traits of the four genotypes of the $F_{2: 3}, F_{3: 4}$, and $F_{4: 5}$ lines.

\begin{tabular}{|c|c|c|c|c|c|c|c|c|c|}
\hline Progeny & $\begin{array}{l}\text { Genotype/ } \\
\text { variety }\end{array}$ & $\begin{array}{l}\text { Spike } \\
\text { length } \\
\text { (cm) }\end{array}$ & $\begin{array}{l}\text { Spikelet } \\
\text { spike }^{-1}\end{array}$ & $\begin{array}{c}\text { Number of } \\
\text { efficient } \\
\text { spikes plant }^{-1}\end{array}$ & $\begin{array}{l}\text { Grain No. } \\
\text { spike }^{-1}\end{array}$ & $\begin{array}{c}\text { Thousand } \\
\text { kernel } \\
\text { weight (g) }\end{array}$ & $\begin{array}{c}\text { Plant } \\
\text { yield* (g) }\end{array}$ & $\begin{array}{c}\text { Plant } \\
\text { biomass* } \\
\text { (g) }\end{array}$ & Harvest index \\
\hline $\mathrm{F}_{2: 3}$ & RRPP & $9.9 \pm 0.4 c$ & $19.0 \pm 0.5 b$ & $8.5 \pm 3.1 \mathrm{a}$ & $44.0 \pm 3.9 b$ & $41.6 \pm 2.7 b$ & $14.3 \pm 1.9 \mathrm{a}$ & $34.2 \pm 3.7 c$ & $0.42 \pm 0.04 a$ \\
\hline \multirow[t]{5}{*}{ 2014-2015 } & RRpp & $11.2 \pm 0.7 b$ & $19.6 \pm 0.8 a$ & $8.0 \pm 3.0 \mathrm{a}$ & $46.1 \pm 3.2 \mathrm{a}$ & $37.3 \pm 2.7 \mathrm{c}$ & $13.0 \pm 1.9 b$ & $36.0 \pm 4.3 c$ & $0.36 \pm 0.03 c$ \\
\hline & $\operatorname{rrPP}$ & $10.8 \pm 0.6 b$ & $19.0 \pm 1.0 b$ & $6.6 \pm 2.2 b$ & $39.5 \pm 3.3 d$ & $45.4 \pm 2.9 a$ & $15.1 \pm 3.0 \mathrm{a}$ & $40.2 \pm 4.2 b$ & $0.38 \pm 0.03 b$ \\
\hline & rrpp & $12.4 \pm 1.0 \mathrm{a}$ & $20.0 \pm 1.0 a$ & $7.0 \pm 2.4 b$ & $42.2 \pm 3.5 c$ & $42.2 \pm 3.3 b$ & $14.6 \pm 3.0 \mathrm{a}$ & $42.5 \pm 5.6 a$ & $0.34 \pm 0.03 c$ \\
\hline & Karcagi & $12.3 \pm 1.1$ & $20.0 \pm 1.2$ & $9.9 \pm 2.4$ & $49.6 \pm 4.2$ & $34.1 \pm 2.8$ & $12.3 \pm 1.8$ & $33.9 \pm 4.8$ & $0.36 \pm 0.04$ \\
\hline & Jinmai47 & $9.9 \pm 0.3$ & $20.5 \pm 0.6$ & $6.2 \pm 1.8$ & $46.8 \pm 4.2$ & $46.2 \pm 3.0$ & $15.7 \pm 1.9$ & $41.7 \pm 4.5$ & $0.39 \pm 0.03$ \\
\hline$F_{3: 4}$ & RRPP & $9.7 \pm 0.5 d$ & $18.5 \pm 1.0 \mathrm{c}$ & $6.3 \pm 2.2 \mathrm{a}$ & $40.3 \pm 3.5 b$ & $40.2 \pm 3.3 b$ & $13.8 \pm 1.2 \mathrm{a}$ & $35.0 \pm 3.6 d$ & $0.39 \pm 0.02 a$ \\
\hline \multirow[t]{5}{*}{ 2015-2016 } & RRpp & $11.5 \pm 1.0 \mathrm{~b}$ & $19.5 \pm 1.0 b$ & $6.6 \pm 1.8 \mathrm{a}$ & $42.6 \pm 4.1 \mathrm{a}$ & $34.5 \pm 3.6 c$ & $11.4 \pm 1.6 b$ & $38.6 \pm 3.3 c$ & $0.30 \pm 0.03 c$ \\
\hline & rrPP & $10.6 \pm 0.6 c$ & $18.6 \pm 0.5 c$ & $5.4 \pm 1.0 b$ & $38.7 \pm 3.8 c$ & $44.3 \pm 4.1 \mathrm{a}$ & $15.4 \pm 2.1 \mathrm{a}$ & $41.3 \pm 3.8 a$ & $0.37 \pm 0.03 b$ \\
\hline & rrpp & $12.7 \pm 0.4 a$ & $20.6 \pm 0.7 a$ & $5.1 \pm 2.0 b$ & $39.6 \pm 2.6 c$ & $40.6 \pm 3.4 b$ & $14.0 \pm 1.7 a$ & $43.6 \pm 4.0 a$ & $0.32 \pm 0.03 c$ \\
\hline & Karcagi & $12.6 \pm 0.3$ & $19.0 \pm 1.0$ & $10.0 \pm 3.2$ & $51.0 \pm 5.2$ & $33.7 \pm 3.8$ & $10.9 \pm 2.0$ & $35.8 \pm 4.4$ & $0.30 \pm 0.03$ \\
\hline & Jinmai47 & $11.2 \pm 0.5$ & $20.3 \pm 0.6$ & $7.0 \pm 1.5$ & $49.3 \pm 3.9$ & $48.4 \pm 4.0$ & $15.2 \pm 2.5$ & $38.1 \pm 3.2$ & $0.41 \pm 0.03$ \\
\hline $\mathrm{F}_{4: 5}$ & RRPP & $10.0 \pm 0.4 d$ & $19.5 \pm 0.5 b$ & $8.0 \pm 2.8 \mathrm{a}$ & $43.0 \pm 5.1 b$ & $43.5 \pm 2.7 c$ & $15.0 \pm 2.0 \mathrm{a}$ & $36.5 \pm 2.5 d$ & $0.41 \pm 0.03 a$ \\
\hline \multirow[t]{5}{*}{ 2016-2017 } & RRpp & $11.0 \pm 0.6 b$ & $20.0 \pm 0.7 a$ & $7.7 \pm 2.5 a$ & $45.0 \pm 5.0 \mathrm{a}$ & $35.5 \pm 3.2 d$ & $12.7 \pm 1.7 \mathrm{c}$ & $39.6 \pm 3.4 c$ & $0.32 \pm 0.02 c$ \\
\hline & rrPP & $10.6 \pm 0.7 c$ & $19.0 \pm 1.1 b$ & $6.6 \pm 2.3 b$ & $39.0 \pm 4.7 d$ & $48.3 \pm 3.6 a$ & $16.0 \pm 1.3 a$ & $42.5 \pm 3.8 b$ & $0.38 \pm 0.03 b$ \\
\hline & rrpp & $11.9 \pm 0.5 a$ & $20.5 \pm 0.8 a$ & $6.2 \pm 2.2 b$ & $41.3 \pm 4.3 c$ & $45.1 \pm 4.1 b$ & $14.4 \pm 2.3 b$ & $45.6 \pm 4.4 a$ & $0.32 \pm 0.03 c$ \\
\hline & Karcagi & $13.0 \pm 1.0$ & $21.0 \pm 0.6$ & $9.0 \pm 2.4$ & $50.2 \pm 4.1$ & $36.2 \pm 3.3$ & $11.5 \pm 1.8$ & $34.0 \pm 3.6$ & $0.34 \pm 0.02$ \\
\hline & Jinmai47 & $10.1 \pm 0.2$ & $21.5 \pm 0.8$ & $6.6 \pm 1.6$ & $47.0 \pm 4.3$ & $50.5 \pm 4.4$ & $16.0 \pm 2.0$ & $41.0 \pm 3.3$ & $0.41 \pm 0.04$ \\
\hline
\end{tabular}

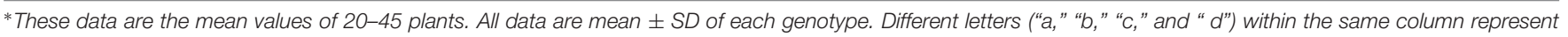
differences significant at $P<0.05$; parents were not included.

Rht12 significantly reduced the thousand kernel weight in both the PP and pp lines in all the three generations. However, Ppd-D1a significantly increased the thousand kernel weight in both the dwarf and tall lines. The thousand kernel weight of the PP lines was significantly higher by an average of $6.0 \mathrm{~g}(16.9 \%)$ and $3.4 \mathrm{~g}(7.9 \%)$ than that of the pp lines in the dwarf and tall groups, respectively, across the three generations (Table 5).

In the three generations, the rrPP group produced the highest plant yield, while the RRpp group exhibited the lowest plant yield among the four groups, and no significance was observed between the RRPP and rrPP groups. Additionally, in the dwarf groups, plant yield of RRPP was higher by an average of $2.0 \mathrm{~g}$ (9.7\%) than that of RRpp across the three generations. In the tall lines, plant yield of rrPP lines was higher by an average of $1.2 \mathrm{~g}$ $(8.2 \%)$ than that of rrpp lines, though it was only significant in $\mathrm{F}_{4: 5}$. The tall lines ( $\mathrm{rr}$ ) achieved a larger plant biomass than the dwarf lines (RR). Finally, RRPP lines achieved the highest harvest index among the four groups. It was clear that the combination of $\mathrm{RR}$ and PP had the potential for increasing plant yield and harvest index (Table 5).

\section{Additive Interaction Between Rht12 and Ppd-D1}

Lines with the dwarf allele at Rht12 flowered $37.9^{\circ} \mathrm{Cd}$ later than the tall lines, while lines with the early (photoperiodinsensitive) allele at $P p d-D 1$ flowered $171.6^{\circ} \mathrm{Cd}$ earlier than the late allele (Table 6). However, lines with both alleles (dwarf-early) flowered earlier than the tall-late lines (lines with both the tall allele at $R h t 12$ and the late allele at $P p d-D 1)$ by approximately $133.7^{\circ} \mathrm{Cd}$, suggesting that the early allele of $P p d-D 1$ can rescue the delaying effect of $R h t 12$ on flowering time and there were additive interaction effects between Rth12 and Ppd-D1 on flowering time. This effect was also observed at different spike development phases. Additionally, lines with the dwarf allele at $R h t 12$ were $48.7 \mathrm{~cm}$ shorter than that with the tall allele, whereas lines with the early (photoperiod-insensitive) allele at $P p d-D 1$ were $9.9 \mathrm{~cm}$ shorter than that with the late allele. However, lines with both alleles (dwarf-early) showed an even shorter plant height compared with the tall-late lines by approximately $58.5 \mathrm{~cm}$ (Table 6), indicating that there were additive interaction effects between Rth12 and Ppd-D1 on plant height.

\section{DISCUSSION}

This study is part of a series of efforts to obtain a better understanding of the dwarf gene Rht12 and to promote its use in wheat improvement (Chen et al., 2013, 2014). In previous studies, the effects of Rht12 on spike development and a range of agronomic traits were analyzed comprehensively (Worland et al., 1994; Wojciechowski et al., 2009; Rebetzke et al., 2012a; Chen et al., 2013). To improve the late ear emergence and flowering time of cultivars with the dwarf allele Rht12, (Worland et al., 1994; Chen et al., 2013), the photoperiod-insensitive allele ( $P p d-$ $\mathrm{D} 1 \mathrm{a}$ ) was introduced in this study. Homozygous $\mathrm{F}_{2: 3}, \mathrm{~F}_{3: 4}$, and $\mathrm{F}_{4: 5}$ lines on the two genes (RRPP, RRpp, rrPP, and rrpp) were chosen to assess the interactive effects of Rht12 and Ppd-D1a on plant development, plant height, and other agronomic traits and to know whether Ppd-D1a could promote spike development in Rht12 dwarf plants. Although the homozygous $\mathrm{F}_{2: 3}, \mathrm{~F}_{3: 4}$, and $\mathrm{F}_{4: 5}$ lines may have different backgrounds compared with 
TABLE 6 | Comparison of the lines with Rht12 and Ppd-D1 to explain the interaction effect for anthesis-associated traits and plant height.

\begin{tabular}{|c|c|c|c|c|c|c|}
\hline Gene & Genotype & SW-DR $\left({ }^{\circ} \mathrm{Cd}\right)$ & DR-TS $\left({ }^{\circ} \mathrm{Cd}\right)$ & TS-AN $\left({ }^{\circ} \mathrm{Cd}\right)$ & SW-AN ( $\left.{ }^{\circ} \mathrm{Cd}\right)$ & Height $(\mathrm{cm})$ \\
\hline \multirow[t]{3}{*}{ Rht12 } & dwarf & 798.1 & 188.0 & 635.6 & 1611.8 & 64.9 \\
\hline & tall & 756.3 & 170.5 & 645.4 & 1573.9 & 113.6 \\
\hline & difference & $41.8^{*}$ & $17.5^{*}$ & $-9.8^{*}$ & $37.9^{*}$ & $-48.7^{*}$ \\
\hline \multirow[t]{3}{*}{ Ppd-D1 } & early & 767.2 & 160.9 & 577.4 & 1507.0 & 84.3 \\
\hline & late & 787.3 & 197.7 & 703.7 & 1678.7 & 94.2 \\
\hline & difference & $-20.1^{*}$ & $-36.8^{*}$ & $-126.4^{*}$ & $-171.6^{*}$ & $-9.9^{*}$ \\
\hline \multirow[t]{3}{*}{ both } & dwarf-early & 788.3 & 170.8 & 571.2 & 1530.2 & 60.8 \\
\hline & tall-late & 766.5 & 190.1 & 707.3 & 1663.9 & 119.3 \\
\hline & difference & $21.7^{*}$ & $-19.3^{*}$ & $-136.2^{*}$ & $-133.7^{*}$ & $-58.5^{*}$ \\
\hline
\end{tabular}

$* P<0.05$.

the near-isogenic lines, the larger number of lines and 3-year replications used in this study could neutralize the effects of other loci and environmental errors to some extent. Good resolution could be achieved due to the strong phenotypic effect of Rht12, as well as other dwarf genes, as approved in our previous studies. (Chen et al., 2013, 2014, 2018; Daoura et al., 2014; Wang et al., 2014, 2015; Yang et al., 2015, 2017).

Previous studies showed that Rht12 could significantly lengthen the duration of sowing to double ridge formation and largely delay the anthesis date, and this delaying effect could not be rescued by the dominant $V r n-B 1$ allele (Chen et al., 2013). The Rht12 dwarf lines needed more time to undergo vernalization and had longer reproductive phases (Chen et al., 2013). Here, it was found that Ppd-D1a could not alter the SW-DR period significantly in the dwarf lines, either. However, after the vegetative phase, spike development of the PP lines became faster than that of the pp lines in both the tall and dwarf lines. Ppd-D1a could significantly shorten the duration of the DR-TS period, especially the duration of the TS-AN period. Finally, PP plants flowered earlier than the pp lines in both height categories. Ppd-D1a rescued the delaying effect of Rht12 on anthesis date. A similar result was reported by Gonzalez et al. (2005) that the duration of the DR-TS and TS-AN periods were significantly shortened by $P p d-D 1 a$ under natural field conditions. Moreover, the vegetative phase (SW-DR period) was also shortened by Ppd-D1a (Gonzalez et al., 2005), though there was no significant difference observed on this trait in our study. The strong effect of $R h t 12$ on vernalization requirement may be the main reason of this difference. Actually, flowering is a complicated trait mainly controlled by vernalization genes $(V r n)$, photoperiod genes $(P p d)$, and developmental rate genes (“earliness per se," Eps). Further effect of $P p d-D 1$ on spike development should be analyzed in this population. Additionally, the delaying effect on flowering time was probably associated with Rht12 rather than being caused by $v r n-A 1$, though $R h t 12$ was closely linked with $v r n-A 1$ on chromosome $5 \mathrm{~A}$ (Worland et al., 1994; Korzun et al., 1997). In fact, the Vrn-A1 loci in the two parents (Karcagi 12 and Jinmai47) are all recessive as determined by marker detection, and the dwarf and tall plants in this study probably shared the same $v r n-A 1$ allele. Therefore, the delaying effect of Rht12 on flowering time might be independent of $v \mathrm{rn}$ A1. Exogenous $\mathrm{GA}_{3}$ could significantly shorten the duration of the SW-DR period as well as other preanthesis phases in the dwarf lines; exogenous $\mathrm{GA}_{3}$ rescued the masking effect of Rht12 on Vrn-B1, which made the dwarf plants with Vrn-B1 display a nearly spring phenotype (Chen et al., 2014). Moreover, exogenous $\mathrm{GA}_{3}$ also restored other dwarf characteristics of $R h t 12$ to normal, suggesting that the Rht12 mutant may be deficient in GA biosynthesis. Therefore, the interactions between Rht12 (gibberellin metabolism) with vernalization and photoperiod genes should be further investigated. Similarly, in barley, the photoperiod gene $P p d-H 1$, which is collinear with the wheat Ppd gene, was also associated with flowering time (Laurie et al., 1995). The dominant alleles at Ppd-H1 confer early flowering under long days but have no effect under short days. In wheat, dominant $P p d$ alleles confer an early flowering phenotype in long day and short day conditions, resulting in yield benefits under certain environments (Cockram et al., 2007). The observation that Arabidopsis has similar floral responses to photoperiod and vernalization suggests that genes identified within its flowering pathways could play orthologous roles in temperate cereals. The interaction of the flowering control genes in wheat and barley with the circadian clock mechanism would also appear to be a fertile area for study in relation to crop improvement. In Arabidopsis, PRR genes have been implicated in providing adaptive responses to photoperiod in growth at different latitudes by modulating circadian timing (Michael et al., 2003). Plants in which the clock period is correctly matched to the day/night cycle are more photosynthetically efficient and productive than those grown in mismatched environments (Dodd et al., 2005).

The number of fertile florets is determined at the TS-AN phase, and hence this phase is particularly important for grain yield (Fischer, 1975; Flintham and Gale, 1983; Gonzalez et al., 2005; Rebetzke et al., 2012a). Lengthening the TS-AN duration in wheat would increase the number of fertile florets and finally improve yield potential (Slafer et al., 1990; Gonzalez et al., 2005). In this study, the $P p d-D 1 b$ plants (pp) achieved higher survival of florets and higher fertility than the Ppd-D1a plants (PP) in both dwarf and tall lines, probably due to the longer TSAN duration (Gonzalez et al., 2005). However, the Rht12 dwarf plants, especially the RRPP plants, which had the shortest TSAN duration, achieved more fertile florets per spike than the tall plants, although the total number of florets initiated was less 
than that of the tall plants. This may be caused by the dwarf stature reducing the competition between the stem and spikes, and this could facilitate more dry matter transport to spikes during the TS-AN period, and in turn could result in producing more fertilized florets and grains per spike (Miralles et al., 1998; Rebetzke et al., 2012a; Chen et al., 2013).

It has been reported that $P p d-D 1 a$ typically advances flowering (Worland, 1996; Bentley et al., 2013; Wilhelm et al., 2013) and is associated with fewer spikelets per ear (Worland et al., 1994, 1998), reduced tillering (Worland et al., 1998), and reduced plant height by approximately $15.0 \%$ (Wilhelm et al., 2013). These effects were also observed in this study, and $P p d-D 1 a$ showed a significant reduction effect $(9.7 \mathrm{~cm}, 10.2 \%)$ on plant height, though it was much weaker than that of Rht12. Similar to that reported before, plant height was reduced by $49.5 \mathrm{~cm}(43.2 \%)$ by $R h t 12$ in this study (Rebetzke et al., 2012a; Chen et al., 2013). However, $P p d-D 1 a$ has a similar reduction effect on plant height as the wheat dwarf gene Rht8 (7-15\%) (Tang et al., 2009; Rebetzke et al., 2012b; Wang et al., 2015). Actually, Ppd-D1a and $R$ ht 8 are both located on wheat chromosome $2 \mathrm{D}$ and linked closely with each other (Worland, 1996; Pestsova et al., 2002; Gasperini et al., 2012; Chebotar et al., 2013). It was found that Rht 8 contributed a $13 \%$ reduction in plant height, while $P p d$ D1 a showed a 3\% reduction through the analysis of recombinant inbred lines segregating at these two loci (Gasperini et al., 2012). The parent Jinmai47 in the current study contains both the dominant Ppd-D1 allele and the dwarf allele of Rht8, assuming that tight linkage exists between Rht8 and Ppd-D1a in the lines examined in this study, Rht8 is likely the primary cause of the height reduction associated with Ppd-D1a. Moreover, it was also reported that Rht8 is responsible for photoperiod insensitivity (Worland, 1996), and genotypes containing Rht8 were earlymaturing (Li et al., 2009), which may be correlated with Ppd-D1a due to their linkage. Because of the reduced plant stature, the Rht12 dwarf plants (RR), either with Ppd-D1a or Ppd-D1b, had greater lodging resistance than that of the tall plants ( $\mathrm{rr}$ ), while the tall plants with $P p d-D 1 a$ (rrPP) had better resistance to lodging than rrpp plants.

The pleiotropic effects of Rht12 on yield-related traits were evaluated in previous studies (Rebetzke et al., 2012a; Chen et al., 2013). Similar results were found in this study that Rht12 increased the numbers of grains per spike and fertile ears per plant and the harvest index, while decreasing the grain size in both the PP and pp genotypes. It was reported that the reduced grain size was not the primary effect of $R h t$ genes, but probably the results of the competition between the increased ear fertility and grain development under limiting photosynthate availability (Flintham and Gale, 1983). Furthermore, grain size can also be affected by flowering time, because the duration of the grain-filling stage under favorable conditions prior to harvest was shortened by the delayed flowering (Worland et al., 1994). However, Ppd-Dla significantly increased the thousand kernel weight, which may be a subsequence of the decreased number of fertile florets and the longer grain-filling duration of the PP genotypes.

In this study, the earlier flowering of 9-10 days in the PP lines may have benefited grain filling. However, RRPP plants achieved larger thousand kernel weight than RRpp plants, but this increased thousand kernel weight was still shorter than that of the tall plants (rr), indicating that the reduced thousand kernel weight of the Rht12 dwarf lines may be affected by many other factors, such as the smaller size of flag leaf, peduncle, as well as other vegetative organs that probably could not provide enough assimilates available to produce large grains. Thus, for improving the thousand kernel weight of Rht12 dwarf plants, genes involved in grain development should be introduced in the breeding program. Finally, the plant yields of the RRPP, rrPP, and rrpp lines were similar, while RRpp lines achieved the lowest plant yield. However, the RRPP genotype had a larger harvest index than the other three groups due to the higher plant yield and the smaller plant biomass. The effects of Ppd-D1a found in this study were similar to those reported previously (Worland et al., 1998; Foulkes et al., 2004; Guo et al., 2010; Cho et al., 2015; Chen et al., 2018). However, it is clear that the combination of Rht12 and Ppd-D1a has advantages on obtaining a larger grain yield and a higher harvest index, which should be considered in the application of other dwarfing genes in wheat breeding. Moreover, based on the 3-year experiment, two lines named entry 8 and entry 10 in the RRPP category, respectively, were selected for further breeding tests. Entry 8 was the highest yield (15.3 g) line with the third lowest height $(59.1 \mathrm{~cm})$ on average. Entry 10 was the second highest yield line with $15.1 \mathrm{~g}$ on average and $60.7 \mathrm{~cm}$ in height with the most grain number per spike. These two lines were into the advanced selection trials for further tests.

\section{CONCLUSION}

The Ppd-D1a allele could rescue the delaying effect of Rht12 on spike development, and the Rht12 dwarf lines when PpdDla flowered earlier due to the shortened reproductive phase. This could promote the use of Rht12 in wheat improvement. Moreover, the combination of RR and PP had no negative effect on plant yield, and some dwarf lines with good agronomic traits were selected for further use in dwarf and high-yield wheat breeding.

Future prospects: Flowering time is a complex trait in wheat and is influenced by a few major genes controlling vernalization requirement, photoperiod response, intrinsic earliness, as well as numerous small-effect QTL, which facilitate fine-tuning of flowering to different climatic conditions (Hanocq et al., 2004; Langer et al., 2014). Ppd-D1 was found to account for almost half of the genotypic variance in flowering in some genetic background (Langer et al., 2014; Guedira et al., 2016; Würschum et al., 2018). It was also observed in this study that $P p d-D 1$ was the major factor affecting flowering time in both the tall and dwarf plants. However, only one cross (Jinmai47 $\times$ Karcagi) was used in this study, and hence the effects of the different genes associated with flowering and yield from the two parents might not have been rigorously assessed. Therefore, more work is needed to explain the phenotype observed, such as using different genetic backgrounds and conducting experiments in different environments or in combination with other flowering-associated 
genes to achieve a comprehensive understanding of the interactive effects between Ppd-D1 and Rht12 on spike development, plant height, and other agronomic traits. Actually, new work is in progress in our group to obtain a better understanding of the effects of Ppd-D1 in Rht12, Rht5, and Rht14 dwarf plants and to breed earlier flowering dwarf germplasms (Chen et al., 2018).

\section{AUTHOR CONTRIBUTIONS}

LC and YD carried out the experiments. LC, YD, HC, CC, QL, and RM analyzed the data. JL, YY, LL, YC, XQ, HL, and SL assisted in the experiments. Y-GH and LC conceived and designed the experiments and wrote the manuscript. KM, HC, and FY helped revise the manuscript. All authors read and approved the final manuscript.

\section{REFERENCES}

Beales, J., Turner, A., Griffiths, S., Snape, J. W., and Laurie, D. A. (2007). A PseudoResponse Regulator is misexpressed in the photoperiod insensitive Ppd-Dla mutant of wheat (Triticum aestivum L.). Theor. Appl. Genet. 115, 721-733. doi: 10.1007/s00122-007-0603-4

Bentley, A. R., Horsnell, R., Werner, C. P., Turner, A. S., Rose, G. A., Bedard, C., et al. (2013). Short, natural and extended photoperiod response in BC2F4 lines of bread wheat with different Photoperiod-1 (Ppd-1) alleles. J. Exp. Bot. 64, 1783-1793. doi: 10.1093/jxb/ert038

Berry, P. M., Sylvester-Bradley, R., and Berry, S. (2007). Ideotype design for lodging-resistant wheat. Euphytica 154, 165-179. doi: 10.1007/s10681-0069284-3

Botwright, T. L., Rebetzke, G. J., Condon, A. G., and Richards, R. A. (2005). Influence of the gibberellin-sensitive Rht 8 dwarfing gene on leaf epidermal cell dimensions and early vigour in wheat (Triticum aestivum L.). Ann. Bot. 95, 631-639. doi: 10.1093/aob/mci069

Chebotar, G. O., Chebotar, S. V., Motsnyy, I. I., and Sivolap, Y. M. (2013). Clarification of the Rht8-Ppd-D1 gene linkage on the 2D chromosome of winter bread wheat. Cytol. Genet. 47, 70-74. doi: 10.3103/S0095452713020047

Chen, L., Hao, L. G., Condon, A. G., and Hu, Y. G. (2014). Exogenous GA3 application can compensate the morphogenetic effects of the GA-responsive dwarfing gene Rht12 in bread wheat. PLoS One 9:e86431. doi: 10.1371/journal. pone.0086431

Chen, L., Phillips, A. L., Condon, A. G., Parry, M. A., and Hu, Y. G. (2013). GA-responsive dwarfing gene Rht12 affects the developmental and agronomic traits in common bread wheat. PLoS One 8:e62285. doi: 10.1371/journal.pone. 0062285

Chen, L., Yang, Y., Cu, C., Lu, S., Lu, Q., Du, Y., et al. (2018). Effects of Vrn-B1 and Ppd-D1 on developmental and agronomic traits in Rht5 dwarf plants of bread wheat. Field Crops Res. 219, 21-32. doi: 10.1016/j.fcr.2018.01.022

Cho, E. J., Kang, C. S., Jung, J. U., Yoon, Y. M., and Park, C. S. (2015). Allelic variation of Rht-1, Vrn-1 and Ppd-1 in Korean wheats and its effect on agronomic traits. Plant Breed. Biotech. 3, 129-138. doi: 10.9787/PBB.2015.3.2. 129

Cockram, J., Jones, H., Leigh, F. J., O’Sullivan, D., Powell, W., Laurie, D. A., et al. (2007). Control of flowering time in temperate cereals: genes, domestication, and sustainable productivity. J. Exp. Bot. 4, 1-14. doi: 10.1093/jxb/erm042

Daoura, B. G., Chen, L., Du, Y., and Hu, Y. G. (2014). Genetic effects of dwarfing gene Rht-5 on agronomic traits in common wheat (Triticum aestivum L.) and QTL analysis on its linked traits. Field Crops Res. 156, 22-29. doi: 10.1016/j.fcr. 2013.10.007

Dodd, A. N., Salathia, N., Hall, A., Kevei, E., Toth, R., Nagy, F., et al. (2005). Plant circadian clocks increase growth, survival and competitive advantage. Science 309, 630-633. doi: 10.1126/science.1115581

\section{FUNDING}

This work was financially supported by the National Natural Science Foundation of China (Grant No. 31501307); China Postdoctoral Science Foundation (2017M623259); Natural Science Basic Research Plan in Shaanxi Province of China (Program No. 2017JM3022); the sub-project of the 863 Program (2013AA102902) of the Ministry of Science and Technology; the China 111 Project (B12007), of the Ministry of Education of China; and the ACIAR Project (CIM/2005/111) of Australia.

\section{SUPPLEMENTARY MATERIAL}

The Supplementary Material for this article can be found online at: https://www.frontiersin.org/articles/10.3389/fpls.2018.01312/ full\#supplementary-material

Ellis, M. H., Rebetzke, G. J., Azanza, F., Richards, R. A., and Spielmeyer, W. (2005). Molecular mapping of gibberellin-responsive dwarfing genes in bread wheat. Theor. Appl. Genet. 111, 423-430. doi: 10.1007/s00122-005-2008-6

Ellis, M. H., Rebetzke, G. J., Chandler, P., Bonnett, D., Spielmeyer, W., and Richards, R. A. (2004). The effect of different height reducing genes on the early growth of wheat. Funct. Plant Biol. 31, 583-589. doi: 10.1071/FP 03207

Ellis, M. H., Spielmeyer, W., Gale, K. R., Rebetzke, G. J., and Richards, R. A. (2002). "Perfect" markers for the Rht-B1b and Rht-D1b dwarfing genes in wheat. Theor. Appl. Genet. 105, 1038-1042. doi: 10.1007/s00122-002-1048-4

Fischer, R. A. (1975). Yield potential in a dwarf spring wheat and effect of shading. Crop Sci. 15, 607-613. doi: 10.2135/cropsci1975.0011183X001500050002x

Flintham, J. E., Borner, A., Worland, A. J., and Gale, M. D. (1997). Optimizing wheat grain yield: effects of Rht (gibberellin-insensitive) dwarfing genes. J. Agric. Sci. 128, 11-25. doi: 10.1017/S0021859696003942

Flintham, J. E., and Gale, M. D. (1983). The Tom Thumb dwarfing gene Rht3 in wheat. 2. effects on height, yield and grain quality. Theor. Appl. Genet. 66, 249-256. doi: 10.1007/BF00251155

Foulkes, M. J., Sylvester-Bradley, R., Worland, A. J., and Snape, J. W. (2004). Effects of a photoperiod-response gene Ppd-D1 on yield potential and drought resistance in UK winter wheat. Euphytica 135, 63-73. doi: 10.1023/B:EUPH. 0000009542.06773 .13

Fu, D., Szücs, P., Yan, L., Helguera, M., Skinner, J. S., Zitzewitz, J. V., et al. (2005). Large deletions within the first intron in VRN1 are associated with spring growth habit in barley and wheat. Mol. Genet. Genomics 273, 54-65. doi: 10.1007/s00438-004-1095-4

Gardner, J. S., Hess, W. M., and Trione, E. J. (1985). Development of the young wheat spike: a SEM study of chinese spring wheat. Am. J. Bot. 72, 548-559. doi: $10.2307 / 2443587$

Gasperini, D., Greenland, A., Hedden, P., Dreos, R., Harwood, W., and Griffiths, S. (2012). Genetic and physiological analysis of $R h t 8$ in bread wheat: an alternative source of semi-dwarfism with a reduced sensitivity to brassinosteroids. J. Exp. Bot. 63, 4419-4436. doi: 10.1093/jxb/ers138

Gonzalez, F. G., Slafer, G. A., and Miralles, D. J. (2005). Pre-anthesis development and number of fertile florets in wheat as affected by photoperiod sensitivity genes Ppd-D1 and Ppd-B1. Euphytica 146, 253-269. doi: 10.1007/s10681-0059021-3

Grogan, S. M., Browm-Guedira, G., Haley, S. D., McMaster, G. S., Reid, S. D., Smith, J., et al. (2016). Allelic variation in developmental genes and effects on winter wheat heading date in the U.S. Great Plains. PLoS One 11:e0152852. doi: 10.1371/journal.pone.0152852

Guedira, M., Xiong, M., Hao, Y. F., Johnson, J., Harrison, S., Marshall, D., et al. (2016). Heading date QTL in winter wheat (Triticum aestivum L.) coincide with major developmental genes VERNALIZATION1 and PHOTOPERIOD1. PLoS One 11:e0154242. doi: 10.1371/journal.pone.0154242 
Guo, Z., Song, Y., Zhou, R., Ren, Z., and Jia, J. (2010). Discovery, evaluation and distribution of haplotypes of the wheat Ppd-D1 Gene. New Phytol. 185, 841-851. doi: 10.1111/j.1469-8137.2009.03099.x

Hanocq, E., Niarquin, M., Heumez, E., Rousset, M., and Gouis, J. L. (2004). Detection and mapping of QTL for earliness components in a bread wheat recombinant inbred lines population. Theor. Appl. Genet. 110, 106-115. doi: 10.1007/s00122-004-1799-1

Haun, J. R. (1973). Visual quantification of wheat development. Agron. J. 65, 116-119. doi: 10.2134/agronj1973.00021962006500010035x

Hedden, P. (2003). The genes of the green revolution. Trends Genet. 19, 5-9. doi: 10.1016/S0168-9525(02)00009-4

Ibrahim, M. S., Paul, R. B., Harry, D. S., Gordon, J. F., and Chad, K. J. (2009). Thermal time models for estimating wheat phonological development and weather-based relationships to wheat quality. Can. J. Plant Sci. 89, 429-439. doi: 10.4141/CJPS07114

Korzun, V., Roder, M., Worland, A. J., and Borner, A. (1997). Intrachromosomal mapping of genes for dwarfing (Rht12) and vernalization response (Vrn1) in wheat by using RFLP and microsatellite markers. Plant Breed. 116, 227-232. doi: 10.1111/j.1439-0523.1997.tb00987.x

Langer, S. M., Longin, C. F. H., and Würschum, T. (2014). Flowering time control in European winter wheat. Front. Plant Sci. 5:537. doi: 10.3389/fpls.2014. 00537

Laurie, D. A., Pratchett, N., Bezant, J. H., and Snape, J. W. (1995). RFLP mapping of five major genes and eight quantitative trait loci controlling flowering time in a winter $\times$ spring barley (Hordeum vulgare L.) cross. Genome 38, 575-585. doi: 10.1139/g95-074

Law, C. N., Stuka, J., and Worland, A. J. (1978). A genetic study of daylength response in wheat. Heredity 41, 185-191. doi: 10.1038/hdy.1978.87

Li, X. P., Lan, S. Q., Zhang, Y. L., Zhang, J. H., Feng, Y. R., Liu, S. B., et al. (2009). Effects of Rht8, Rht10 and Rht12 semi-dwarfing and dwarfing genes on wheat vegetative and reproductive development. Acta Agric. Bor. Sin. 24, 50-53. doi: 10.7668/hbnxb.2009.S1.013

Liu, Y., Zhang, J., Hu, Y. G., and Chen, J. (2017). Dwarfing genes Rht4 and Rht$B 1 b$ affect plant height and key agronomic traits in common wheat under two water regimes. Field Crops Res. 204, 242-248. doi: 10.1016/j.fcr.2017. 01.020

Michael, T. P., Salome, P. A., Yu, H. J., Spencer, T. R., Sharp, E. L., McPeek, M. A., et al. (2003). Enhanced fitness conferred by naturally occurring variation in the circadian clock. Science 302, 1049-1053. doi: 10.1126/science.1082971

Miralles, D. J., Katz, S. D., Colloca, A., and Slafer, G. A. (1998). Floret development in near isogenic wheat lines differing in plant height. Field Crops Res. 59, 21-30. doi: 10.1016/S0378-4290(98)00103-8

Peng, J., Richards, D. E., Hartley, N. M., Murphy, G. P., Devos, K. M., Flintham, J. E., et al. (1999). 'Green Revolution' genes encode mutant gibberellin response modulators. Nature 400, 256-261. doi: 10.1038/22307

Pestsova, E. G., Korzun, V., and Röder, M. S. (2002). "Pedigree analysis of wheat chromosome 2D," in Proceedings of the 12th International EWAC Workshop, Norwich, 122-124.

Porebski, S., Bailey, L. G., and Baum, B. R. (1997). Modification of a CTAB DNA extraction protocol for plants containing high polysaccharide and polyphenol components. Plant Mol. Biol. Rep. 15, 8-15. doi: 10.1007/BF02772108

Rebetzke, G. J., Appels, R., Morrison, A. D., Richards, R. A., McDonald, G., Ellis, M. H., et al. (2001). Quantitative trait loci on chromosome 4B for coleoptile length and early vigour in wheat (Triticum aestivum L.). Aust. J. Agric. Res. 52, 1221-1234. doi: 10.1071/AR01042

Rebetzke, G. J., Bonnett, D. G., and Ellis, M. H. (2012a). Combining gibberellic acid-sensitive and insensitive dwarfing genes in breeding of higher-yielding, sesqui-dwarf wheats. Field Crops Res. 127, 17-25. doi: 10.1016/j.fcr.2011. 11.003

Rebetzke, G. J., Ellis, M. H., Bonnett, D. G., Mickelson, B., Condon, A. G., and Richards, R. A. (2012b). Height reduction and agronomic performance for selected gibberellin-responsive dwarfing genes in bread wheat (Triticum aestivum L.). Field Crops Res. 126, 87-96. doi: 10.1016/j.fcr.2011.09.022

Rebetzke, G. J., Richards, R. A., Fettell, N. A., Long, M., Condon, A. G., Forrester, R. I., et al. (2007). Genotypic increases in coleoptile length improves stand establishment, vigour and grain yield of deep-sown wheat. Field Crops Res. 100, 10-23. doi: 10.1016/j.fcr.2006.05.001
Rebetzke, G. J., Richards, R. A., Sirault, X. R. R., and Morrison, A. D. (2004). Genetic analysis of coleoptile length and diameter in wheat. Aust. J. Agric. Res. 55, 733-743. doi: 10.1071/AR04037

Shaykewich, C. F. (1995). An appraisal of cereal crop phenology modeling. Can. J. Plant Sci. 75, 329-341. doi: 10.4141/cjps95-057

Slafer, G. A., Andrade, F. H., and Satorre, E. H. (1990). Genetic improvement effects on pre-anthesis physiological attributes related to wheat grain yield. Field Crops Res. 23, 255-263. doi: 10.1016/0378-4290(90)90058-J

Stapper, M., and Fischer, R. A. (1990). Genotype, sowing date and plant spacing influence on high-yielding irrigated wheat in southern New South Wales. II. Growth, yield and nitrogen use. Aust. J. Agric. Res. 41, 1021-1041. doi: 10.1071/ AR9901021

Sun, T. P. (2010). Gibberellin-GID1-DELLA: a pivotal regulatory module for plant growth and development. Plant Physiol. 154, 567-570. doi: 10.1104/pp.110. 161554

Tang, N., Jiang, Y., He, B. R., and Hu, Y. G. (2009). The effects of dwarfing genes (Rht-B1b, Rht-D1b, and Rht8) with different sensitivity to GA (3) on the coleoptile length and plant height of wheat. Sci. Agric. Sin. 8, 1028-1038. doi: 10.1016/S1671-2927(08)60310-7

Waddington, S. R., Cartwright, P. M., and Wall, P. C. (1983). A Quantitative scale of spike initial and pistil development in barley and wheat. Ann. Bot Lond. 51, 119-130. doi: 10.1093/oxfordjournals.aob.a086434

Wang, Y., Chen, L., Du, Y., Yang, Z., Condon, A. G., and Hu, Y. G. (2014). Genetic effect of dwarfing gene Rht 13 compared with Rht-D1b on plant height and some agronomic traits in common wheat (Triticum aestivum L.). Field Crops Res. 162, 39-47. doi: 10.1016/j.fcr.2014.03.014

Wang, Y., Du, Y., Yang, Z., Chen, L., Condon, A. G., and Hu, Y. G. (2015). Comparing the effects of GA-responsive dwarfing genes Rht13 and Rht8 on plant height and some agronomic traits in common wheat. Field Crops Res. 179, 35-43. doi: 10.1016/j.fcr.2015.04.010

Wilhelm, E. P., Boulton, M. I., Al-Kaff, N., Balfourier, F., Bordes, J., Greenland, A. J., et al. (2013). Rht-1 and Ppd-D1 associations with height, GA sensitivity, and days to heading in a worldwide bread wheat collection. Theor. Appl. Genet. 126, 2233-2243. doi: 10.1007/s00122-013-2130-9

Wojciechowski, T., Gooding, M. J., Ramsay, L., and Gregory, P. J. (2009). The effects of dwarfing genes on seedling root growth of wheat. J. Exp. Bot. 60, 2565-2573. doi: 10.1093/jxb/erp107

Worland, A. J. (1996). The influence of flowering time genes on environmental adaptability in European wheats. Euphytica 89, 49-57. doi: 10.1007/BF0001 5718

Worland, A. J., Korzun, V., Roder, M. S., Ganal, M. W., and Law, C. N. (1998). Genetic analysis of the dwarfing gene Rht8 in wheat. Part II. The distribution and adaptive significance of allelic variants at the Rht 8 locus of wheat as revealed by microsatellite screening. Theor. Appl. Genet. 96, 1110-1120. doi: 10.1007/ s001220050846

Worland, A. J., Petrovic, S., and Law, C. N. (1988). Genetic analysis of chromosome 2D of wheat. II: the importance of this chromosome to Yugoslavian varieties. Plant Breed. 100, 247-259. doi: 10.1111/j.1439-0523.1988.tb00250.x

Worland, A. J., Sayers, E. J., and Borner, A. (1994). The genetics and breeding potential of Rht12, a dominant dwarfing gene in wheat. Plant Breed. 113, 187-196. doi: 10.1111/j.1439-0523.1994.tb00722.x

Würschum, T., Langer, S. M., Longin, C., Tucker, M. R., and Leiser, W. L. (2018). A three-component system incorporating Ppd-D1, copy number variation at Ppd-B1, and numerous small-effect quantitative trait loci facilitates adaptation of heading time in winter wheat cultivars of worldwide origin. Plant Cell Environ. 41, 1407-1416. doi: 10.1111/pce.13167

Yan, L., Helguera, M., Kato, K., Fukuyama, S., Sherman, J., and Dubcovsky, J. (2004). Allelic variation at the VRN-1 promoter region in polyploidy wheat. Theor. Appl. Genet. 109, 1677-1686. doi: 10.1007/s00122-0041796-4

Yang, Z., Liu, C., Du, Y., Chen, L., Chen, Y., and Hu, Y. G. (2017). Dwarfing gene Rht18 from tetraploid wheat responds to exogenous GA3 in hexaploid wheat. Cereal Res. Commun. 45, 23-24. doi: 10.1556/0806.44.2016.050

Yang, Z., Zheng, J., Liu, C., Wang, Y., Condon, A. G., Chen, Y., et al. (2015). Effects of the GA-responsive dwarfing gene Rht 18 from tetraploid wheat on agronomic traits of common wheat. Field Crops Res. 183, 92-101. doi: 10.1016/j.fcr.2015. 07.028 
Youssefian, S., Kirby, E. J. M., and Gale, M. D. (1992). Pleiotropic effects of the GA-insensitive Rht dwarfing genes in wheat: effects on leaf, stem, ear and floret growth. Field Crops Res. 28, 191-210. doi: 10.1016/0378-4290(92)90 040-G

Zadoks, J. C., Chang, T. T., and Konzak, C. F. (1974). Decimal code for growth stages of cereals. Weed Res. 14, 415-421. doi: 10.1111/j.1365-3180.1974. tb01084.x

Zhang, X. K., Yang, S. J., Zhou, Y., He, Z. H., and Xia, X. C. (2006). Distribution of the Rht-B1b, Rht-D1b and Rht8 reduced height genes in autumn-sown Chinese wheats detected by molecular markers. Euphytica 152, 109-116. doi: 10.1007/s10681-006-9184-6
Conflict of Interest Statement: The authors declare that the research was conducted in the absence of any commercial or financial relationships that could be construed as a potential conflict of interest.

Copyright $\odot 2018$ Chen, Du, Lu, Chen, Meng, Cui, Lu, Yang, Chai, Li, Liu, Qi, $L i$, Mishina, Yu and $H u$. This is an open-access article distributed under the terms of the Creative Commons Attribution License (CC BY). The use, distribution or reproduction in other forums is permitted, provided the original author(s) and the copyright owner(s) are credited and that the original publication in this journal is cited, in accordance with accepted academic practice. No use, distribution or reproduction is permitted which does not comply with these terms. 